\title{
Radiotherapy Combined with Chemotherapy
Regional Lymph Node Recurrence in Gastric Cancer
}

This article was published in the following Dove Press journal: Cancer Management and Research

\author{
Liang Cai ${ }^{1, *}$ \\ Ganlu Ouyang (iD ${ }^{2, *}$ \\ Xin Wang ${ }^{2}$ \\ Zhiping $\mathrm{Li}^{3}$ \\ Yali Shen ${ }^{2}$ \\ 'Lung Cancer Center, West China School \\ of Medicine, West China Hospital of \\ Sichuan University, Chengdu, People's \\ Republic of China; ${ }^{2}$ Department of \\ Abdominal Oncology, Cancer Center, \\ West China Hospital, Sichuan University, \\ Chengdu, People's Republic of China; \\ ${ }^{3}$ Department of Radiation Oncology, \\ Cancer Center, West China Hospital, \\ Sichuan University, Chengdu, People's \\ Republic of China \\ *These authors contributed equally to \\ this work
}

Correspondence: Yali Shen

Department of Abdominal Oncology, Cancer Center, West China Hospital, Sichuan University, No. 37 of Wainan Guoxue Lane, Wuhou District, Chengdu 6I004I, People's Republic of China Tel/Fax +86 2885422589

Email sylprecious@I63.com
Purpose: Regional lymph node recurrence (RLNR) in gastric cancer is uncommon. We investigated the effects of radiotherapy combined with chemotherapy against limited RLNR and analyzed the regularity of regional lymph node recurrence and metastasis.

Patients and Methods: This retrospective study included 34 gastric cancer patients with limited RLNR after D2 lymphadenectomy between January 2012 and May 2018. All patients received systemic chemotherapy and local radiotherapy with median dose of 52.5 Gy (30-66 Gy in fractions of 1.8-3.0 Gy daily, five times weekly). All sites of recurrent and metastatic lymph nodes were collected and analyzed.

Results: The median follow-up was 19 months (range 7-60 months). After treatment, complete response and partial response were observed in $32.4 \%$ and $55.9 \%$ of patients, respectively. The median overall survival (OS) and progression-free survival (PFS) were 18 months and 13 months. On multivariate analysis, age ( $\leq 60 \mathrm{vs}>60)$ was associated with a significantly better OS $(p=0.025)$ and radiation dose ( $<54$ Gy vs $\geq 54 \mathrm{~Gy}$ ) was considered as an independent prognostic factor for PFS $(\mathrm{p}=0.000)$. During radiotherapy, three patients developed grade 3 gastrointestinal toxicity, and no deaths were related to the treatments. The most commonly metastatic lymph nodes were the No. 4 , No. 3, No. 6, No. 5, No. 7, No. 9, and No. 8 nodes; the recurrent lymph nodes were mainly located in the No. 16b, No. 16a, No. 9, No. 14, No. 7, No. 13, and No. 8 nodes.

Conclusion: The selected gastric cancer patients with limited RLNR may benefit from radiotherapy combined with chemotherapy. High-dose radiotherapy ( $\geq 54 \mathrm{~Gy}$ ) lead to better PFS and tend to extend OS. The major lymph node recurrence sites were in the gastric vascular region (especially No. 16a/b nodes).

Keywords: gastric cancer, radiotherapy, regional lymph node, D2 lymphadenectomy, recurrence

\section{Introduction}

It revealed gastric cancer is the sixth-most common cancer and the third leading cause of cancer-related mortality worldwide from 2018 global cancer statistics. ${ }^{1}$ The prognosis of advanced and metastatic gastric cancer is generally poor and lack of effective treatment. ${ }^{2}$ Growing evidence has suggested that a subset of carefully selected gastric cancer with limited metastatic exists that might achieve a significantly prolonged survival from a multimodality treatment strategy. In a recently published article, the patients with limited metastasis showed a more prolonged survival (median OS 16.7 months) after preoperative chemotherapy followed by surgical resection of metastases than without surgery. ${ }^{3}$ 
In the patterns of recurrence after curative resection, locoregional lymph node recurrence accounts for a small proportion. ${ }^{4,5}$ There is no standard treatment for regional lymph node recurrence (RLNR). Systemic chemotherapy is often recommended for patients. However, chemotherapy alone is not regarded as sufficient for locoregional control. And surgical resection is not preferred for RLNR because of the low resectability. ${ }^{6}$ With radiation development, radiotherapy may play an essential role as a safe and effective local treatment modality. Moreover, few studies investigated the role of RT for RLNR after radical surgery in advanced gastric cancer. Therefore, we screened out gastric cancer patients with RLNR after D2 lymphadenectomy to explore whether radiotherapy combined with chemotherapy could improve clinical outcome and analyze the regularity of regional lymph node recurrence and metastasis.

\section{Patients and Methods}

\section{Patient Characteristics}

We retrospectively studied gastric cancer patients with regional lymph node recurrence treated at our institution between January 2012 and May 2018. The patients selected for this study received radical gastrectomy with D2 lymphadenectomy and had regional lymph node recurrence lesions without any other metastasis. Regional lymph node recurrence is mainly diagnosed by lymph node biopsy or imaging studies, including contrastenhanced computed tomography (CT) and positron emission tomography (PET). In terms of imaging, the diagnosis of recurrent lymph nodes is defined as a short diameter of lymph nodes larger than $1.0 \mathrm{~cm}$ or uptake of fluorine-18-2-fluoro-2-deoxy-d-glucose (FDG). We collected all available clinical data of these patients, including history, treatment, imaging, and follow-up.

\section{Treatment}

Chemotherapy was recommended after regional lymph node recurrence was performed for patients in this study. Because the optimal regimen remains to be defined, heterogeneous chemotherapy regimens were performed depending on the patient's status and the medical oncologist's preference. We divided the patients into two groups according to the chemotherapy regimen: group 1: dual agents chemotherapy (XELOX/SOX/TP) and group 2: single agent chemotherapy (Docetaxel/Irinotecan/Paclitaxel).

The timing of radiotherapy was fixed according to the patient's status and the physician's judgment. Immediate radiotherapy was defined as starting radiotherapy within eight weeks after the diagnosis of regional lymph node recurrence. The CT scan was performed for radiotherapy planning with immobilization devices. A scan thickness of $3 \mathrm{~mm}$ was used. All patients received radiotherapy with 6 MV linear accelerator using intensity-modulated radiotherapy (IMRT). The gross tumor volume (GTV) of recurrent lymph nodes was determined by the CT scan that showed the position and size of involved lymph nodes. Adjacent regional nodal area was described as clinical target volume (CTV). Planned target volume (PTV) denoted the CTV and $0.6 \mathrm{~cm}-1 \mathrm{~cm}$ margins for geometric uncertainties.

\section{Assessment of Response, Survival and Toxicity}

We positioned distribution of recurrent lymph nodes on the CT image and measured their maximum degree change during the follow-up. The regression of the tumor was considered as a response to the treatment. And the response was evaluated using the Response Evaluation Criteria in Solid Tumors (RECIST) ver. 1.1. Overall survival (OS) and progression-free survival (PFS) were calculated from the time of diagnosis of lymph node recurrence.

Adverse events caused by chemotherapy were evaluated by the National Cancer Institute Common Terminology Criteria for Adverse Events version 3.0. Acute and chronic toxicities associated with radiotherapy were assessed according to the Radiation Therapy Oncology Group (RTOG) criteria (version 2.0).

\section{Statistical Analysis}

Ordinal data are presented as numbers and percentages. Kaplan-Meier method was used to draw the OS and PFS curve and conduct univariate analysis. Statistically significant variables in univariate analysis were used to conduct multivariate analysis with COX proportional risk model. Statistically significant was defined as $\mathrm{P}<0.05$. All statistical analyses were performed using SPSS, version 22.0 (IBM Corp., Armonk, NY, USA).

\section{Results}

\section{Patient Characteristics}

During the period, a total of gastric cancer 34 patients with regional lymph node recurrence were retrieved. The median age of the patients was 57.8 years old (range 41-78 years). Most patients (67.6\%) were in ECOG 0-1, and the others $(32.4 \%)$ patients were in ECOG 2. There were 14 
(41.1\%) patients with clinical symptoms. The most common symptom was abdominal or back pain, which was rated moderate to severe. There were 19 patients with high lymph node positive rate that was greater than 0.25 . "Lymph node positive rate" was defined as the ratio of positive lymph nodes to the total number of removed lymph nodes in D2 lymphadenectomy. Patients' characteristics are presented in Table 1.

A total of 34 patients received both radiotherapy and chemotherapy after regional lymph node recurrence. The median total dose to GTV was 52.5 Gy (range, 30 to 66 Gy), with fractions of 1.8 to $3.0 \mathrm{~Gy}$ once, five times per week. The dose received by 18 patients was $\geq 54 \mathrm{~Gy}$. Twenty patients received dual agents chemotherapy and the remaining 14 patients received single agent chemotherapy. Seventeen patients received immediate radiotherapy.

\section{Patterns of Recurrence}

At the time of recurrence, lymph node mainly occurred in No. $16 \mathrm{~b}$ nodes $(76 \%)$ and No. $16 \mathrm{a}$ nodes $(56 \%)$. Meanwhile, No. 9 nodes (32\%), No. 14 nodes (29\%), No.7 nodes (26\%), No. 13 nodes $(24 \%)$, and No. 8 nodes $(21 \%)$ are secondly mainly metastatic position.

Moreover, we analyzed the location of pathologically confirmed metastatic lymph nodes in all patients after surgery. It shows that metastatic lymph nodes occur mainly in the perigastric lymph nodes, including No. 4 nodes (50\%), No. 3 nodes (38\%), No. 6 nodes (35\%), No. 5 nodes $(26 \%)$, No. 7 nodes (41\%), No. 9 nodes $(29 \%)$, and No. 8 nodes (24\%). Details of lymph node distribution are shown in Figure 1.

\section{Response to Treatment}

All 34 patients with abdominal LN metastasis who received radiation, 11 patients (32.4\%) showed a complete response and 19 patients (55.9\%) showed partial response, resulting in an objective regression rate of $88.3 \%$. Other 4 patients $(11.8 \%)$ had stable disease control. Among the symptomatic patients, 11 patients (78.6\%) experienced pain relief after the radiotherapy.

\section{Survival and Prognostic Factors}

The median follow-up was 19 months (range 7-60 months). The median OS and PFS were 18 months and 13 months (Figure 2), with 91.2\% 1-yr OS (\%) and 70.6\% 1-yr PFS (\%). On univariate analysis, five factors appeared to be associated with OS: age, lymph node-positive rate, chemotherapy regimens, immediate radiotherapy and radiation
Table I Patient and Tumor Characteristics

\begin{tabular}{|c|c|c|}
\hline Elements & Groups & No. of Patients \\
\hline \multirow[t]{3}{*}{ Sex } & & \\
\hline & Male & 18 \\
\hline & Female & 16 \\
\hline \multirow[t]{3}{*}{ Age } & & \\
\hline & $\leq 60$ & 20 \\
\hline & $>60$ & 14 \\
\hline \multirow[t]{3}{*}{ ECOG performance status } & & \\
\hline & $0-1$ & 23 \\
\hline & 2 & II \\
\hline \multirow[t]{3}{*}{ Symptoms } & & \\
\hline & Absent & 20 \\
\hline & Present & 14 \\
\hline \multirow[t]{4}{*}{ Tumor location } & & \\
\hline & Cardia & 7 \\
\hline & Gastric body & 12 \\
\hline & Pylorus & 15 \\
\hline \multirow[t]{3}{*}{ T stage } & & \\
\hline & TI-T2 & 6 \\
\hline & T3-T4 & 28 \\
\hline \multirow[t]{3}{*}{ Lymph node positive rate } & & \\
\hline & $<0.25$ & 15 \\
\hline & $\geq 0.25$ & 19 \\
\hline \multirow[t]{3}{*}{ Pathological type } & & \\
\hline & Carcinoma & 18 \\
\hline & SRCC & 16 \\
\hline \multirow[t]{3}{*}{ Neurovascular infiltration } & & \\
\hline & Negative & 24 \\
\hline & Positive & 10 \\
\hline \multirow[t]{3}{*}{ Chemotherapy regimen } & & \\
\hline & Group I & 20 \\
\hline & Group 2 & 14 \\
\hline \multirow[t]{3}{*}{ Immediate radiotherapy } & & \\
\hline & Yes & 17 \\
\hline & No & 17 \\
\hline \multirow[t]{3}{*}{ Radiotherapy dose } & & \\
\hline & $<54 G y$ & 16 \\
\hline & $\geq 54 G y$ & 18 \\
\hline
\end{tabular}

Abbreviations: ECOG, Eastern Cooperative Oncology Group; SRCC, signet-ring cell carcinoma.

dose. On multivariate analysis, younger age $(\leq 60$ vs $>60)$ was associated with a significantly better OS (HR 0.425; 95\% CI $0.200-0.900 ; p=0.025)$. Additionally, higher radiation dose ( $<54$ Gy vs $\geq 54 \mathrm{~Gy}$ ) has a tendency to get better survival (OS HR 2.864; 95\% CI 1.000-8.202; $\mathrm{p}=0.050$ ). 


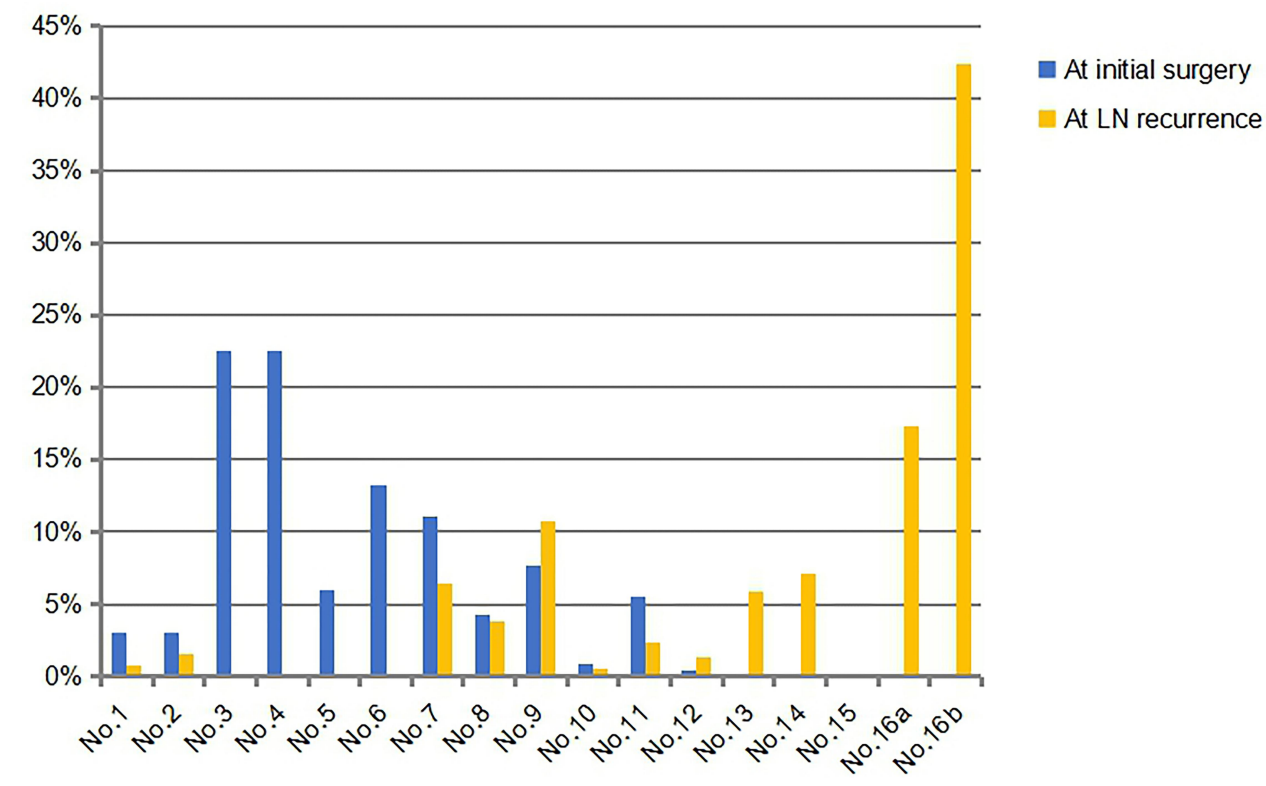

Figure I Distribution of lymph nodes in patients after surgery and distribution of metastatic lymph nodes.

Abbreviation: LN, lymph nodes.

Univariate analyses, age, lymph node-positive rate, chemotherapy regimens, immediate radiotherapy, and radiation dose are related to PFS. And radiation dose $(<54 \mathrm{~Gy}$ vs $\geq 54 \mathrm{~Gy}$ ) was proved to be an independent prognostic factor for PFS (HR 15.985; 95\% CI 3.546-72.049; $\mathrm{p}=0.000$ ). The full details of univariate and multivariate analyses of OS and PFS are provided in Tables 2 and 3.

\section{Treatment Toxicities}

The toxicity of treatment was tolerable. In the course of radiotherapy, acute gastrointestinal toxicity was observed in all patients. The most common symptoms were nausea and vomiting, with Grade 1 in 19 (55.9\%), Grade 2 in 12 (35.3\%), and Grade 3 in 3 (8.8\%). For neutropenia, 27 patients experienced $1-2$ grade toxicities and grade $\geq 3$ neutropenia was observed in remaining seven patients. No deaths were related to chemoradiotherapy.

\section{Discussion}

Lymph node recurrence after gastrectomy is uncommon in clinical practice. ${ }^{7}$ Due to the different biological behavior of gastric cancer and the complexity of RLNR, there is a lack of high-level clinical evidence. The aims of this study are to evaluate the safety and efficacy of RT with chemotherapy for selected patients with abdominal LN involvement alone from gastric cancer after D2 lymphadenectomy.

Perioperative treatment is recommended for advanced gastric cancer patients following the evidence from
MAGIC and MRC trials. ${ }^{8,9}$ Prospective study studies have shown that surgery combined with perioperative chemotherapy can effectively prolong the survival of oligometastatic gastric cancer patients. ${ }^{10}$ No standard treatment has been established yet for patients with RLNR after radical surgery for gastric cancer. In most cases, recurrences after gastrectomy are considered unsuitable for reoperation due to the low resectability and postoperative complications. ${ }^{11,12}$ With the development of systemic therapy and radiation technique, successful abdominal recurrence management using radiotherapy combined with chemotherapy has been reported. Sun et al reported the median OS in the chemoradiotherapy group was 11.4 months, while in the chemotherapy group was 4.8 months $(\mathrm{P}=0.002)$ for gastric cancer patients with lymph node recurrence. ${ }^{13}$ Kim et al reported that the radiotherapy group's survival time was much longer than that of the chemotherapy group (36 months vs 16 months; $\mathrm{P}=$ 0.007). ${ }^{14}$ Lee et al demonstrated that PFS of the radiotherapy group was superior to that of the non-radiotherapy group ( 25 vs 8 months; $\mathrm{P}=0.021$ ), and OS showed an increasing trend in the radiotherapy group (29 vs 20 months; $\mathrm{P}=0.095) .{ }^{15}$ In this study, our data also demonstrate that OS and PFS were significantly associated with chemoradiotherapy: 13 months PFS and 18 months OS.

Improvements in local control and survival were associated with the increase of the radiation dose. In this study, IMRT is applied for all patients and IGRT is also used 
A

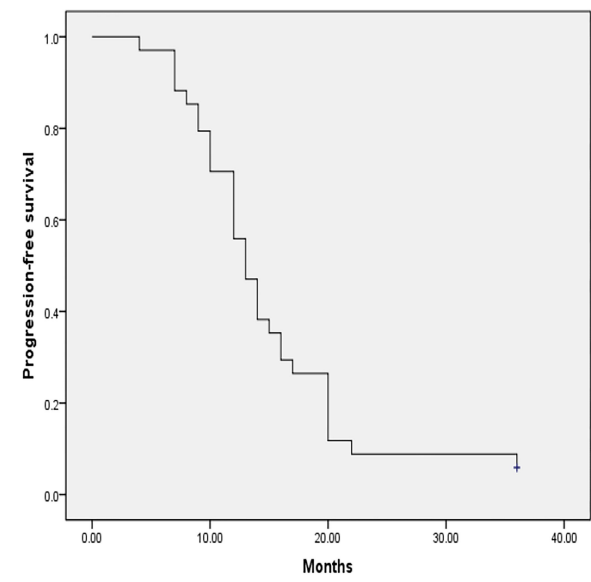

No. at risk

\section{C}

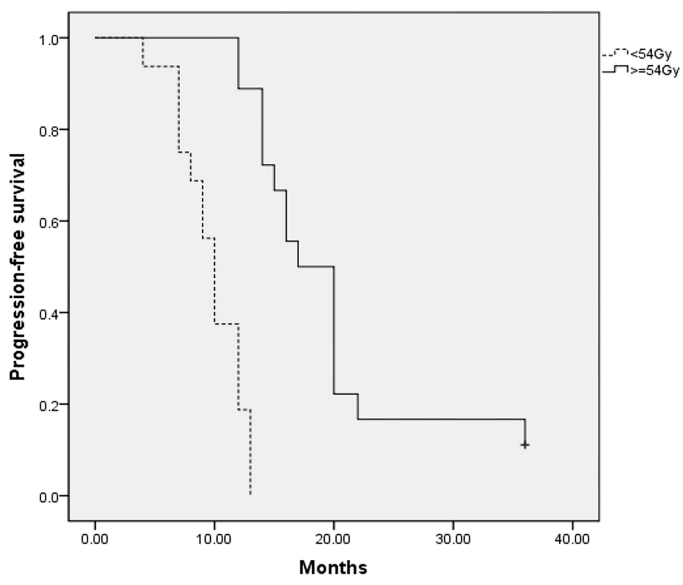

No. at risk

$<54 G y$

$\geqslant 54$ Gy

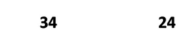

B

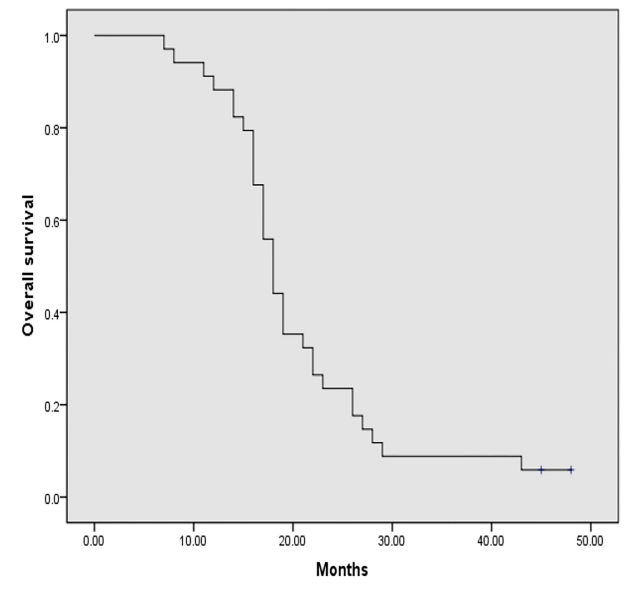

No. at risk

D

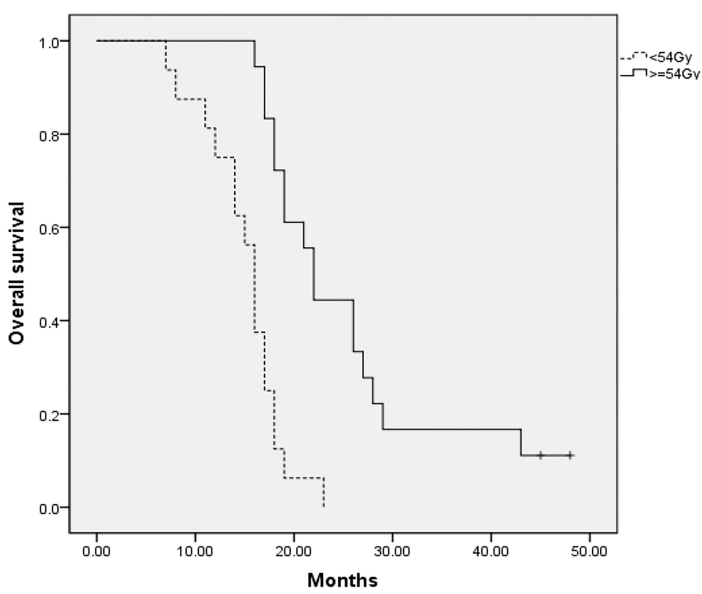

No. at risk

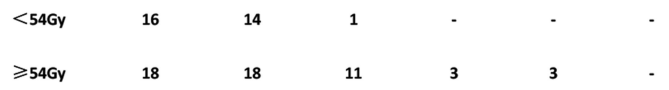

Figure 2 (A and B) Progression-free survival and overall survival of all patients. (C) Progression-free survival for patients with $<54 \mathrm{~Gy}$ and $\geq 54 \mathrm{~Gy}$ radiation dose group. (D) Overall survival for patients with $<54 \mathrm{~Gy}$ and $\geq 54$ Gy radiation dose group.

when necessary. The median dose to GTV was 52.5 Gy and 18 patients received radiation dose above $54 \mathrm{~Gy}$. The objective regression rate reached $88.3 \%$ (including $11 \mathrm{CR}$ and 19 PR). Meanwhile, the toxicity related with radiation was tolerated, resulting from IMRT which decreased volume and radiation dose of gastrointestinal tissue around GTV. For prognostic factors, higher radiation dose ( $\geq 54$ Gy) is a positive prognostic factor for PFS and had a tendency to obtain better OS.

Not all metastatic gastric cancer may achieve longterm control if using aggressive multimodality strategies. ${ }^{16}$ So the proper selection of advanced gastric cancer patients who is more likely to benefit from a combined approach is the key to optimize treatment outcome. In this study, the physical state of patients is good with ECOG $\leq 2$, and the median number of lymph node recurrence was 3 (from 1 to 8), which was regarded as oligometastatic lesions. Based on the above results, the efficacy of radiotherapy for RLNR can be preliminarily confirmed, but it still needs to be clarified by prospective randomized study.

D2 lymphadenectomy has a wide range of lymphatic dissection. However, 21.8-49.5\% of gastric cancer patients who received surgery also experienced 
Table 2 Univariate Analysis for Prognostic Factors of Survival

\begin{tabular}{|c|c|c|c|c|c|}
\hline Variables & $\begin{array}{l}\text { No. of } \\
\text { Patients }\end{array}$ & $\begin{array}{l}\text { I-Yr } \\
\text { PFS } \\
\text { (\%) }\end{array}$ & p-value & $\begin{array}{l}\text { I-Yr } \\
\text { OS } \\
(\%)\end{array}$ & p-value \\
\hline \multicolumn{6}{|l|}{ Sex } \\
\hline Male & 18 & 72.2 & 0.716 & 88.9 & 0.982 \\
\hline Female & 16 & 68.8 & & 93.8 & \\
\hline \multicolumn{6}{|l|}{ Age } \\
\hline$\leq 60$ & 20 & 85.0 & 0.020 & 100.0 & 0.007 \\
\hline$>60$ & 14 & 50.0 & & 85.7 & \\
\hline \multicolumn{6}{|l|}{ ECOG } \\
\hline $0-1$ & 23 & 65.2 & 0.505 & 91.3 & 0.469 \\
\hline 2 & 22 & 81.8 & & 90.9 & \\
\hline \multicolumn{6}{|l|}{ Symptoms } \\
\hline Absent & 20 & 75.0 & 0.146 & 100.0 & 0.058 \\
\hline Present & 14 & 64.3 & & 78.6 & \\
\hline \multicolumn{6}{|l|}{ Tumor location } \\
\hline Cardia & 7 & 75.0 & 0.505 & 100.0 & 0.549 \\
\hline Gastric body & 12 & 75.0 & & 91.7 & \\
\hline Pylorus & 15 & 64.3 & & 85.7 & \\
\hline \multicolumn{6}{|l|}{ T stage } \\
\hline $\mathrm{TI}-\mathrm{T} 2$ & 6 & 66.7 & $0.08 \mathrm{I}$ & 100.0 & 0.073 \\
\hline T3-T4 & 28 & 71.4 & & 89.3 & \\
\hline \multicolumn{6}{|l|}{ Lymph node } \\
\hline \multicolumn{6}{|l|}{ positive rate } \\
\hline$<0.25$ & 15 & 100.0 & 0.000 & 100.0 & 0.000 \\
\hline$\geq 0.25$ & 19 & 47.4 & & 84.2 & \\
\hline \multicolumn{6}{|l|}{$\begin{array}{l}\text { Pathological } \\
\text { type }\end{array}$} \\
\hline Carcinoma & 18 & 66.7 & 0.733 & 94.4 & 0.840 \\
\hline SRCC & 16 & 75.0 & & 87.5 & \\
\hline \multicolumn{6}{|l|}{ Neurovascular } \\
\hline \\
\hline Negative & 24 & 66.7 & 0.688 & 91.7 & 0.978 \\
\hline Positive & 10 & 80.0 & & 90.0 & \\
\hline \multicolumn{6}{|l|}{$\begin{array}{l}\text { Chemotherapy } \\
\text { regimen }\end{array}$} \\
\hline Group I & 20 & 80.0 & 0.009 & 95.0 & 0.031 \\
\hline Group 2 & 14 & 57.1 & & 85.7 & \\
\hline \multicolumn{6}{|l|}{ Immediate } \\
\hline \multicolumn{6}{|l|}{ radiotherapy } \\
\hline Yes & 17 & 94.1 & 0.000 & 94.1 & 0.002 \\
\hline No & 17 & 47.1 & & 88.2 & \\
\hline \multicolumn{6}{|l|}{$\begin{array}{l}\text { Radiotherapy } \\
\text { dose }\end{array}$} \\
\hline$<54 G y$ & 16 & 37.5 & 0.000 & 81.3 & 0.000 \\
\hline$\geq 54 G y$ & 18 & 88.9 & & 100.0 & \\
\hline
\end{tabular}

Abbreviations: OS, overall survival; PFS, progression-free survival; ECOG, Eastern Cooperative Oncology Group; SRCC, signet-ring cell carcinoma. recurrence. ${ }^{17-19}$ The recurrence pattern of D2 lymphadenectomy should be further clarified. Only one study from South Korea has explored the lymph node recurrence pattern for gastric cancer after D2 lymphadenectomy. $^{20}$ Our study analyzed both the lymph node metastasis patterns at the time of initial surgery and recurrence pattern in all patients. The results showed the difference between the lymph node metastasis pattern and recurrence pattern: No. 1 nodes to No.6 nodes have high metastasis rate and low recurrence rate, No.7 nodes to No.9 nodes have high metastasis rate and high recurrence rate, and No.10 nodes to No.16 nodes have the trend of low metastasis rate and high recurrence rate. In all, the recurrent lymph nodes were mainly located in the gastric vascular region, like No.9 nodes (32\%), No.14 nodes (29\%), No.7 nodes (26\%), No.13 nodes (24\%), and No. 8 nodes (21\%). Meanwhile, some lymph nodes areas had a relatively rare recurrence, like splenic hilum (No.10) and below the superior mesenteric artery (No.14a). Notably, No.16a/b nodes were the most common recurrence $(56 \%$ and $76 \%)$ region regardless of location of primary tumor. The results of Yoon et al were consistent with our study, No. 16a/b nodes were most likely to relapse after D2 lymphadenectomy. ${ }^{20}$ What is more, a Phase III study conducted by Sasako et al showed no significant difference in survival rate between gastric cancer patients received with addition of para-aortic nodal dissection to D2 lymphadenectomy compared with patients received with D2 lymphadenectomy alone. ${ }^{21}$ In addition, compared with D2 lymphadenectomy alone, the addition of para-aortic nodal dissection to D2 lymphadenectomy does not significantly increase the rate of surgical complications. Therefore, it is valuable to discuss the benefited patients from paraaortic nodal dissections. Moreover, in our study, there was higher recurrence occurred in No.16a/b nodes in $\mathrm{N} 2 / \mathrm{N} 3$ patients compared to $\mathrm{N} 0 / \mathrm{N} 1$ patients. So it is necessary to further explore the factors related to No16a/b nodes recurrence after D2 lymphadenectomy.

Limited by the number of gastric cancer patients with regional lymph node recurrence after D2 lymphadenectomy, sample size is small and no control group was set in this retrospective study. For rare disease, like gastric cancer patients with limited RLNR, it is better to carry out multicenter clinical research to obtain more clinical experience. 
Table 3 Multivariate Analysis for Overall Survival and Progression-Free Survival

\begin{tabular}{|c|c|c|c|c|c|c|}
\hline \multirow[t]{2}{*}{ Variables } & \multicolumn{3}{|c|}{ Progression-Free Survival } & \multicolumn{3}{|c|}{ Overall Survival } \\
\hline & HR & $95 \% \mathrm{Cl}$ & P-value & HR & $95 \% \mathrm{Cl}$ & P-value \\
\hline $\begin{array}{l}\text { Age } \\
\qquad 600 \\
>60\end{array}$ & $0.5 \mathrm{II}$ & $0.242-|.08|$ & 0.079 & 0.425 & $0.200-0.900$ & 0.025 \\
\hline $\begin{array}{l}\text { Lymph node positive rate } \\
\qquad 0.25 \\
\geq 0.25\end{array}$ & 0.535 & $0.169-1.698$ & 0.288 & 0.397 & $0.134-1.172$ & 0.094 \\
\hline $\begin{array}{l}\text { Chemotherapy regimen } \\
\text { Group } 1 \\
\text { Group } 2\end{array}$ & 0.502 & $0.224-1.124$ & 0.094 & 0.945 & $0.384-2.329$ & 0.903 \\
\hline $\begin{array}{l}\text { Immediate radiotherapy } \\
\text { Yes } \\
\text { No }\end{array}$ & 0.595 & $0.225-1.572$ & 0.295 & 0.953 & $0.297-3.059$ & 0.936 \\
\hline $\begin{array}{l}\text { Radiotherapy dose } \\
\quad<54 \text { Gy } \\
\geq 54 G y\end{array}$ & 15.985 & $3.546-72.049$ & 0.000 & 2.864 & $1.000-8.202$ & 0.050 \\
\hline
\end{tabular}

Abbreviations: $\mathrm{HR}$, hazard radio; $\mathrm{Cl}$, confidence interval.

\section{Conclusion}

In conclusion, these patients with limited regional lymph node recurrence benefit from multimodality treatment strategies, including radiotherapy combined with chemotherapy. Besides, high-dose radiotherapy ( $\geq 54$ Gy) lead to better PFS and tend to extend OS. The major lymph node recurrence sites were in the gastric vascular region (especially No. 16a/b nodes), which is valuable to discuss the benefited patients from paraaortic nodal dissections.

\section{Ethical Approval}

Ethical approval was obtained from Ethics committee on Biomedical Research, West China Hospital of Sichuan University (2020-908). Patient consent to review their medical records was not required. The reasons for the waiver were as follows. Firstly, this is a retrospective study. There was no additional risk to patients. In the process of ethical approval, we have submitted to the ethics committee the application for exemption from informed consent of patients. Additionally, we abided by the Declaration of Helsinki. We collected de-identified data of patients. And the final results of the study would be anonymity.

\section{Acknowledgments}

This research was supported by project of the Science and Technology Department in Sichuan province (2019YJ0142).

\section{Disclosure}

The authors report no conflicts of interest in this work.

\section{References}

1. Bray F, Ferlay J, Soerjomataram I, Siegel RL, Torre LA, Jemal A. Global cancer statistics 2018: GLOBOCAN estimates of incidence and mortality worldwide for 36 cancers in 185 countries. CA Cancer J Clin. 2018;68(6):394-424. doi:10.3322/caac.21492

2. Wagner AD, Syn NL, Moehler M, et al. Chemotherapy for advanced gastric cancer. Cochrane Database Syst Rev. 2017;8:CD004064.

3. Carmona-Bayonas A, Jimenez-Fonseca P, Echavarria I, et al. Surgery for metastases for esophageal-gastric cancer in the real world: data from the AGAMENON national registry. Eur J Surg Oncol. 2018;44 (8):1191-1198. doi:10.1016/j.ejso.2018.03.019

4. Liu D, Lu M, Li J, et al. The patterns and timing of recurrence after curative resection for gastric cancer in China. World J Surg Oncol. 2016;14(1):305. doi:10.1186/s12957-016-1042-y

5. Yoo CH, Noh SH, Shin DW, Choi SH, Min JS. Recurrence following curative resection for gastric carcinoma. Br J Surg. 2000;87 (2):236-242. doi:10.1046/j.1365-2168.2000.01360.x

6. Song KY, Park SM, Kim SN, Park CH. The role of surgery in the treatment of recurrent gastric cancer. Am J Surg. 2008;196(1):19-22. doi:10.1016/j.amjsurg.2007.05.056

7. Chang JS, Lim JS, Noh SH, et al. Patterns of regional recurrence after curative D2 resection for stage III (N3) gastric cancer: implications for postoperative radiotherapy. Radiother Oncol. 2012;104(3):367-373. doi:10.1016/j.radonc.2012.08.017

8. Cunningham D, Allum WH, Stenning SP, et al. Perioperative chemotherapy versus surgery alone for resectable gastroesophageal cancer. $N$ Engl J Med. 2006;355(1):11-20. doi:10.1056/NEJMoa055531

9. Cuschieri A, Weeden S, Fielding J, et al. Patient survival after D1 and D2 resections for gastric cancer: long-term results of the MRC randomized surgical trial. Surgical Co-operative Group. $\mathrm{Br} J$ Cancer. 1999;79(9-10):1522-1530. doi:10.1038/sj.bjc.6690243 
10. Al-Batran SE, Homann N, Pauligk C, et al. Effect of neoadjuvant chemotherapy followed by surgical resection on survival in patients with limited metastatic gastric or gastroesophageal junction cancer: the AIO-FLOT3 trial. JAMA Oncol. 2017;3(9):1237-1244. doi:10.1001/ jamaoncol.2017.0515

11. Lehnert T, Rudek B, Buhl K, Golling M. Surgical therapy for loco-regional recurrence and distant metastasis of gastric cancer. Eur J Surg Oncol. 2002;28(4):455-461. doi:10.1053/ejso.2002.1260

12. Badgwell B, Cormier JN, Xing Y, et al. Attempted salvage resection for recurrent gastric or gastroesophageal cancer. Ann Surg Oncol. 2009;16(1):42-50. doi:10.1245/s10434-008-0210-x

13. Sun J, Sun YH, Zeng ZC, et al. Consideration of the role of radiotherapy for abdominal lymph node metastases in patients with recurrent gastric cancer. Int $J$ Radiat Oncol Biol Phys. 2010;77 (2):384-391. doi:10.1016/j.ijrobp.2009.05.019

14. Kim BH, Eom KY, Kim JS, Kim HH, Park DJ. Role of salvage radiotherapy for regional lymph node recurrence after radical surgery in advanced gastric cancer. Radiat Oncol J. 2013;31(3):147-154. doi:10.3857/roj.2013.31.3.147

15. Lee J, Yoon HI, Rha SY, et al. Integration of radiotherapy and chemotherapy for abdominal lymph node recurrence in gastric cancer. Clin Transl Oncol. 2017;19(10):1268-1275. doi:10.1007/ s12094-017-1665-7
16. Salati M, Valeri N, Spallanzani A, Braconi C, Cascinu S. Oligometastatic gastric cancer: an emerging clinical entity with distinct therapeutic implications. Eur J Surg Oncol. 2019;45 (8):1479-1482. doi:10.1016/j.ejso.2018.11.006

17. Lee SE, Ryu KW, Nam BH, et al. Prognostic significance of intraoperatively estimated surgical stage in curatively resected gastric cancer patients. J Am Coll Surg. 2009;209(4):461-467. doi:10.1016/j. jamcollsurg.2009.06.001

18. Nurwidya F, Takahashi F, Takahashi K. Meeting report: current cancer perspectives from the 9(th) Annual Meeting of the Japanese Society of Medical Oncology. Thorac Cancer. 2012;3(1):94-97. doi:10.1111/j.1759-7714.2011.00076.x

19. $\mathrm{Wu} \mathrm{CW}$, Lo SS, Shen $\mathrm{KH}$, et al. Incidence and factors associated with recurrence patterns after intended curative surgery for gastric cancer. World J Surg. 2003;27(2):153-158. doi:10.1007/s00268-002-6279-7

20. Yoon HI, Chang JS, Lim JS, et al. Defining the target volume for post-operative radiotherapy after D2 dissection in gastric cancer by CT-based vessel-guided delineation. Radiother Oncol. 2013;108 (1):72-77. doi:10.1016/j.radonc.2013.05.025

21. Sasako M, Sano T, Yamamoto S, et al. D2 lymphadenectomy alone or with para-aortic nodal dissection for gastric cancer. $N$ Engl J Med. 2008;359(5):453-462. doi:10.1056/NEJMoa0707035

\section{Publish your work in this journal}

Cancer Management and Research is an international, peer-reviewed open access journal focusing on cancer research and the optimal use of preventative and integrated treatment interventions to achieve improved outcomes, enhanced survival and quality of life for the cancer patient.
The manuscript management system is completely online and includes a very quick and fair peer-review system, which is all easy to use. Visit http://www.dovepress.com/testimonials.php to read real quotes from published authors. 